\title{
HEALING SERPIGINOUS ULCER OF THE CORNEA BY TOTAL CONJUNCTIVAL HOODING*
}

\author{
BY \\ A. MiKLós \\ Szombathely, Hungary.
}

TREATMENT for serpiginous ulcer is a problem of ophthalmology which has not been adequately solved hitherto. As the literature reveals, it is a most interesting question for ophthalmologists. There is no bactericide, no theoretically promising operative method that has not been used to treat this disease. But most of these, however promising they seemed, generally proved no more efficacious than the methods known previously.

These failures are perhaps responsible for the fact that even a recent text-book, Thiel's "Lehrbuch der Augenheilkunde" (1948), in referring to operative methods for serpiginous ulcer, enumerates only obsolete and unsatisfactory methods such as cauterization, paracentesis, or Saemisch's keratotomy, without even mentioning the others. The conservatism of this text-book may also be due to the reason given by Brückner (1949) in his comments on Stein's lecture. Brückner says that grave cases of serpiginous ulcer are rarely seen in Switzerland. Since the prognosis is fairly good in most cases of incipient serpiginous ulcer, the writer of the chapter in question probably never saw that the operations he enumerates were not successful in grave cases. Almost every clinic has its own method of treating serpiginous ulcer, but these are generally of no avail in severe cases, as can be seen in the literature.

\section{Earlier Methods of Treatment}

The treatment for serpiginous ulcer may be conservative or operative.

Before penicillin was discovered and used, the conservative method consisted of local treatment : painting the ulcer with 20 per cent. $\mathrm{ZnSO}_{4}$, sulphonamide drops or ointments, the administration of ethylmorphinhydrochloricum to increase the metabolism of the cornea, instillation of optochin hydrochloricum and other bactericide drugs into the conjunctival sac. Besides local treatment heteroprotein and sulphonamides may be given. Lately almost all the authors writing on the treatment of serpiginous ulcer have resorted to different systems of penicillin administration, a question I shall refer to later.

\footnotetext{
* Received for publication October 21, 1949.
} 
The conservative therapy having been unsuccessful in many cases, new operative methods were devised.

Paracentesis soon proved to yield no satisfactory results.

Wessely (1926) tried to destroy the bacteria by steam cauterization. Before carrying out total hooding systematically, we used Wessely's method in many cases, but we were not satisfied with the results. In our experience this method may be effective with incipient ulcers, but not in severe cases. It even occurred that after steam cauterization the ulcer grew rapidly owing to exsiccation of the tissues.

Saemisch's keratotomy is generally resorted to as ultimum refugium. We saw panophthalmitis in more than one case as a consequence of this coarse method. When the progression of the ulcer came to a standstill after all, a thick adherent leucoma was present. We believe that in most cases this operation has no influence upon the growth of the ulcer.

Sondermann (1922) wanted to ensure the permanent escape of the aqueous by trephining the ulcer. By increasing the production of antibodies he hoped to promote healing of the ulcer. Before total hooding was introduced we saw in several cases that progression became definitely slower after the ulcer had perforated spontaneously. But in these cases too, the final result, after a long treatment, was severe leucoma or panophthalmitis. We believe that Sondermann's trephining across a section containing virulent bacteria is not without danger. We must also keep in mind that the lens may easily be injured by the trephining of the ulcer, the cornea having become thinner in an unequal way. Thus it seems improbable that this method would be often used in the therapy of serpiginous ulcer.

Similarly the results of hooding with a conjunctival flap as recommended by Kuhnt-Brückner are unsatisfactory. This method has been used with slight alterations by Löhlein (1931), Clausen (1931), Erggelet (1931), Rubbrecht (1931), Clerici (1934), and others, but it could not yield good results because of disadvantages to be discussed later in this paper.

\section{Total Hooding}

In 1941 I recommended a new and successful method for healing serpiginous ulcers : total hooding of the cornea with the conjunctiva. This operation devised for the healing of Mooren's ulcer, was published by Kreiker in 1933. At that time I had already reported 25 cases of severe serpiginous ulcer which had been successfully hooded in the course of one year. My publication had few repercussions in the literature, however, except for a report by Iawaetz (1943) of six cases of serpiginous ulcer successfully 
treated by this method. In 1948, Kettesy (Kreiker) published the excellent results obtained at the Eye Clinic of Debrecen.

This efficacious method was not widely used for various reasons, one being that the circulation of my paper was restricted during the second world war. The principal reason for its neglect, however, was Meisner's incorrect report in Thiel's "Ophthalmologische Öperationslehre" (1942), vol. I. Although I had referred exactly to the chapter in question in Blaskovics and Kreiker's "Eingriffe am Auge" (2nd ed., 1945), Meisner's description of total hooding was not correct, and in consequence good results could not be obtained. Meisner says that in several cases in which total hooding had been carried out the ulcer had spread underneath the conjunctival flap. I can only reply that this happens very rarely indeed, and then only when the operation has not been performed in the right way. Kettesy (Kreiker) has not seen this complication in 56 cases, and I who have made more than a hundred total hoodings have seen it only in two very severe cases, both of them treated before the discovery of penicillin. The final results were evisceration in one case and a pea-sized staphyloma covered with conjunctiva in the other. Two losses only in so many cases prove that total hooding is an excellent method for healing one of the most malignant inflammations of the cornea.

Meisner obviously misunderstood the fundamental principle of total hooding when he reported that the sutures were knotted above the cornea. What he describes is not total hooding, but Kuhnt's double flap with all that operation's drawbacks, to which I shall later refer. The punctum saliens of total hooding is that by strongly anchoring the flap to the sclerotic below the limbus, we may gain time for the flap to adhere to the ulcer.

There is another reason why this method is not more popular : it is in strict contradiction to the classic principle of $u b i p u s, i b i$ evacua. I confess that I too was somewhat sceptical at first, and that I took great care to observe whether the good results were not due to some coincidence. But my experience during more than eight years has convinced me that total conjunctival hooding is the most efficacious method for the treatment of serpiginous ulcer.

\section{Technique}

After anaesthetizing with 1 per cent. pontocaine or 5 per cent. cocaine, the palpebral fissure is opened with Hess' or some other usual speculum. The bulbar conjunctiva is swelled by a 2 per cent. novocaine solution and then circumcised with Cooper's scissors along the limbus (Fig. 1). The circumcised conjunctiva is undermined as far as the upper fornix together with Tenon's capsule until the cornea can be covered by the prepared flap without tension. Then the conjunctiva under the limbus is pushed back so that the sclerotic below is bare to an extent of $3-4 \mathrm{~mm}$. in breadth. With a fixation forceps of medium strength-in order to fix the bulbus-the inferior rectus is grasped, and with a convex knife incisions 
$2 \mathrm{~mm}$. long and a quarter of the sclerotic deep are made at $4.30,6$, and 7.30 o'clock in the places designed for anchoring. For the sutures $5 / 0$ catgut is used, first because it is soft and does not cut through the conjunctiva, secondly because

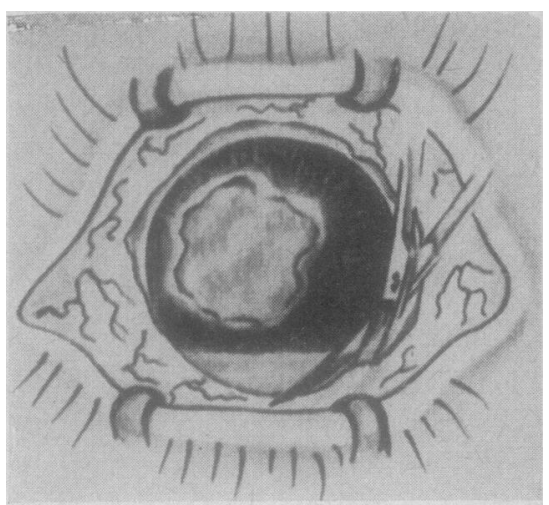

FIG. 1.--Circumcision of the raised bulbar conjunctiva in the limbus.

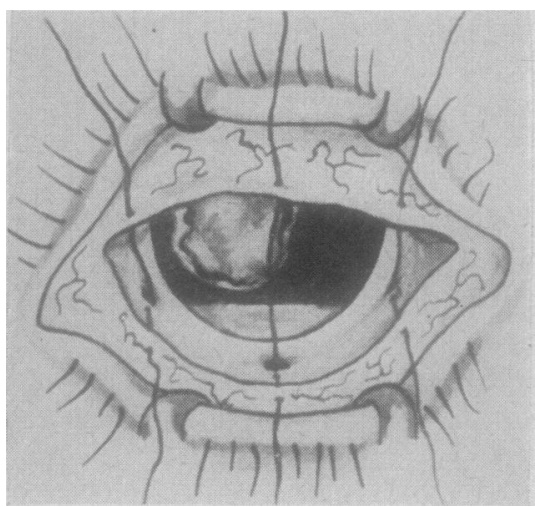

FIG. 2.-The prepared conjunctiva after insertion of the sutures. Anchoring in the sclerotic at $7.30,6$, and 4.30 o'clock.

it is resorbed and does not require removal. Thin silk or nylon suiures are quite suitable too. After the incision into the sclerotic, three sutures are inssted into the upper part of the flap about $2 \mathrm{~mm}$. from the margin of the wound opposite the proposed anchoring.

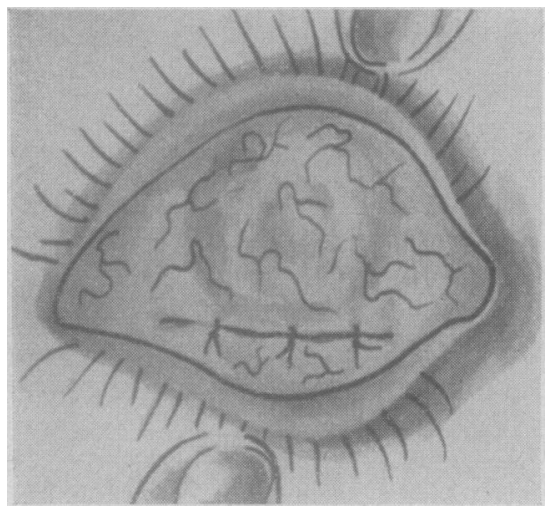

FIG. 3. - Total hooding completed. Sutures anchored in the sclerotic $2 \mathrm{~mm}$. below the limbus. Then, grasping the muscle again, the sutures are anchored to the sclerotic through the wound in the prepared sclera. Suturing is continued through the conjunctiva so as to place the sutures at $2 \mathrm{~mm}$. from the lower wound margin of the bulbar conjunctiva (Fig. 2). The sutures are then pushed aside and the ulcer is curetted with a fine Meyhöfer spoon in such a way as to remove the necrotic and disintegrated parts as far as possible. The undermined layer of the cornea covering the margin is dissected with fine scissors if necessary, and thus this part can also be cleaned. (With abscesses of the cornea the abscess must be opened first. After removal of the covering layer of cornea, the cavity is cleaned. The further treatment is the same as for serpiginous ulcer.) After removal of the ulcer the hood is closed with knotted sutures (Fig. 3). The first day the patient should be kept in bed and wear a binocular bandage, but from the second day onwards the operated eye is kept open.

\section{Complications}

Complications during the operation are rare. It may happen that there are scars on the conjunctiva owing to some previous 
disease, so that it is difficult to draw down the flap. 'This can be dealt with by incisions into the upper part of the taut conjunctiva. It also occurs sometimes that the cornea-if very thin-is perforated during the operation, but this is not a serious disturbance. Since perforation generally occurs during the anchoring to the sclerotic, it is advisable to use very fine, thin needles. If, despite all precautionary measures, perforation occurs, the patient is kept in bed for a few days in order to promote the restoration of the chamber.

As Kettesy also affirms, the state of the patient usually shows a remarkable change even on the first day after the operation. The pains subside and the eye becomes quiet, so that special postoperative treatment is not necessary. But with grave ulcers this is not always the case and lately we have ensured the success of the operation by the administration of heteroprotein and penicillin which have proved very helpful in cases which threatened to become refractory. Mydriatics should always be given to keep the pupil dilated until complete recovery. Warm compresses of camomile infusion may be used to promote healing by hyperaemia.

Patients with a totally hooded serpiginous ulcer must remain in hospital for much shorter a time than those who are treated in the conservative way. Kettesy found that while the latter had to remain in hospital for an average of a fortnight, the former needed medical attendance for 6 days only. If we deduct the time necessary for the healing of the removed lacrimal sac and only consider the duration of medical attendance required for the healing of the hood, this may be reduced to 4 days. To these we must add the time which the patient has to spend in hospital after removal of the hood, because only then can we consider our therapy as complete. Kettesy says therefore that the average for medical attendance of a totally hooded serpiginous ulcer is seven days. This is just about half the time required for cases treated conservatively. Thus not only is the treatment shorter, but also the patients are able to return to work much sooner. Of course the cases we publish had to have longer medical attendance, because they were the gravest.

Removal of the Hooding.-Kettesy says that this may be done after six months. We believe, however, that it is not necessary to wait so long. If the eye is pale and quiet the hood can be safely removed 8 to 12 weeks after the operation. We must allow that much time at least for the filling of the corneal ulcer, for the removal of the destroyed cell débris, and for the strengthening of the new granulation tissue. When the hood was removed too early, we observed renewed inflammation and hypopyon in more than one case. We must assume that this was due to the fact that 
strong chemotaxis sets in owing to the diffusion of toxins from the bacteria present as saprophytes in the conjunctival sac. These toxins penetrate through the area of the granulation tissue which is not yet sufficiently dense, having been bereft of its epithelium for formation of the hood. The time required for healing depends on the extent and depth of the ulcer. These factors must be considered individually in choosing the moment for removing the hood. But however long we wait, we have to be prepared for strong irritation in most cases when the ulcer has been very large. This keratitis is however responsive to heteroprotein and the usual local treatment.

After anaesthetization with 1 per cent. pontocaine or 5 per cent. cocaine the hood can be easily detached from the cornea with scissors, forceps, and keratome, as it adheres only to the site of the ulcer. After opening there remain about $3-4 \mathrm{~mm}$. of superfluous conjunctiva. Before, this used to be cut. According to our new practice we shave off the superfluous conjunctiva from Tenon's capsule and separate it as far as the upper fornix in order to eliminate the shortening of the latter caused by the hood. The conjunctival flap which has been severed is pushed upwards until the margin of the superfluous part reaches the limbus. Then a doubly-armed suture is placed in the conjunctiva and the ends, having been passed through the corresponding places of the upper eye-lid, are knotted above the skin. On the next day the suture may be removed, because conjunctiva is firmly held in place by fibrin. Further treatment is that usually given for keratitis.

\section{Case Reports}

Case 1.-Sz. J., a peasant aged 66 years. His left eye had been painful for a week. He knew of no injury. He had not seen a doctor. Admitted June 2, 1945.

Diagnosis: ulcus serpens corneae cum hypopyo et dacryocystitis chronica 1.s.

Visual acuity right eye $5 / 5$, left eye movements of hand.

Bacteriological report: pneumococcus.

For two days the usual local treatment was given (painting with $\mathrm{ZnSO}_{4}, 1$ per cent., optochin, 10 per cent., argyrol, 0.02 per cent. scopolamine, 5 per cent. dion:n drops). The lacrimal sac was immediately removed and the patient was given 0.1 cc. typhus vaccine (as heteroprotein) intravenously.

Temperature $103 \cdot 1^{\circ} \mathrm{F}$. But despite treatment progression continued. On June 5 we carried out a total hooding. The next day the eye was quiet and healed uneventfully in 10 days.

The patient returned after three months for opening of the hood with a pale and quiet eye. The removal of the hood presented no complications, and after the usual local treatment (scopolamine, dionin, argyrol and compresses) the patient recovered in six days. V.A. after removal of the hood, right eye $5 / 5$; left eye, only movement of hand. We intended to carry out an optical iridectomy, but the patient never came back, although he was asked to do so.

Case 2.- V. J., a woman aged 50 years. Her left eye had been painful for a week. She had been once to see a doctor, who told her to go to hospital immediately, but she did not come until a week later. Her eye was in a very 
grave state; the ulcer not only occupied three quarters of the cornea, but was also very deep. There was a hypoyon of about $4 \mathrm{~mm}$. in the chamber. The lacrimal sacs were normal.

Bacteriological report: pneumococcus.

V.A. right eye $5 / 5$; left eye, perception of light.

Hooding was carried out immediately. During the operation the very thin cornea became perforated. The next day the eye was fairly quiet, but for the sake of safety the patient was given a typhus injection of $0.1 \mathrm{cc}$. intravenously. Temperature $103.8^{\circ} \mathrm{F}$. Because of the perforation the patient had to remain in bed for five days. Recovery was uneventful, and she left nine days after hooding.

The patient reported for opening three months later, with a perfectly quiet eye. The flap covered the cornea completely. Opening was normal. Afterwards a strong irritation-due to a large erosion-set in with a small hypopyon, which healed, however, in one week after administration of heteroprotein and local treatment. The patient's state is now V.A. right eye $5 / 5$; left eye, movements of hand. We advised corneal transplantation, but she refused to have it performed.

Case 3.-T. F., a peasant aged 74, applied for admission on August 29, 1945, saying he had been having pains in his left eye for three days. He had not seen a doctor.

Diagnosis: Ulcus serpens corneae cum hypopyo et dacryocystitis chronica 1.s. Cataracta progrediens o.d.

V.A. right eye $5 / 50$, uncorrectable; left eye, movements of hand.

Bacteriological report: pneumococcus.

The lacrimal sac was immediately removed, and for a few days the usual conservative treatment was carried out, but the ulcer continued to grow. By September 2 the ulcer was of medium depth, undermined, its margin extending inwards. Total hooding was performed without any complications. The next day the eye was quiet and remained open. The usual treatment was given. On the third day the eye became slightly irritated and the flap began to swell, but after an injection of heteroprotein (temperature $102^{\circ} \mathrm{F}$.) it healed within six days. About two weeks later the right eye was operated on for cataract with good result.

The patient did not return to hospital before the spring of 1948 . After opening had been performed only a very fine scar was visible in place of the ulcer on the temporal side of the cornea. V.A. right eye, with adequate correction $5 / 8$; left eye $5 / 20$.

On June 14, 1949, patient came again, saying that his left eye was blind. Diagnosis : Cataracta totalis o.s. After operation for cataract V.A. left eye, with adequate correction, $5 / 15$.

Case 4.-K. M., a quarryman 47 years old, applied for admission on May 7 , 1947. His right eye had been injured by a stone splinter five days previously. He had been treated for two days by a doctor, who sent him to hospital when his condition deteriorated.

V.A. right eye $1 / 50$; left eye $5 / 12$, uncorrectable. The lacrimal sacs were normal.

Diagnosis: Ulcus serpens corneae cum hypopyo o.d., macula corneae o.s.

Bacteriological report: pneumococcus.

For two days the patient was given penicillin drops at intervals of 15 minutes in day time and 30 minutes at night (1 cc. 5,000 units) and heteroprotein (typhus vaccine which caused a temperature of $104^{\circ} \mathrm{F}$.). Despite the treatment the ulcer continued to grow with only slightly diminished rapidity. As an experiment $10 \times 30,000$ units sodium penicillin were administered subconjunctivally within 24 hours, but hardly influenced the growth of the ulcer. After five days of more or less ineffective treatment with penicillin, a total hooding was successfully performed although the conjunctiva had become very irritated and friable. On the following day the eye was quiet and the pains had ceased. After the usual post-operative treatment the patient left hospital eight days later, having completely recovered.

He returned on February 26, 1948, for removal of the hood with a perfectly quiet eye. After an uneventful opening strong irritation set in which subsided, 
however, after local treatment and administration of heteroprotein within seven days. His present condition is V.A. right eye 5/30, uncorrectable; left eye 5/12, uncorrectable.

Case 5.-K. A., a locksmith 30 years old, was admited to hospital on September 18, 1947. While at work on September 9 his forehead had been severely injured by the recoiling arm of a crane. He had been treated for fractura baseos cranii at the surgical department of another hospital. According to the surgeons an ulcer had developed on the 3rd or 4th day of his unconsciousness (probably as a consequence of lagophthalmos) and was unresponsive to conservative treatment.

When the patient was admitted his left cornea showed a medium deep ulcer the size of a large lentil at 6 o'clock, with a necrotic floor, of yellowish-white colour, with a typical progressing margin and a hypopyon of about $2 \mathrm{~mm}$. The lacrimal sacs were normal.

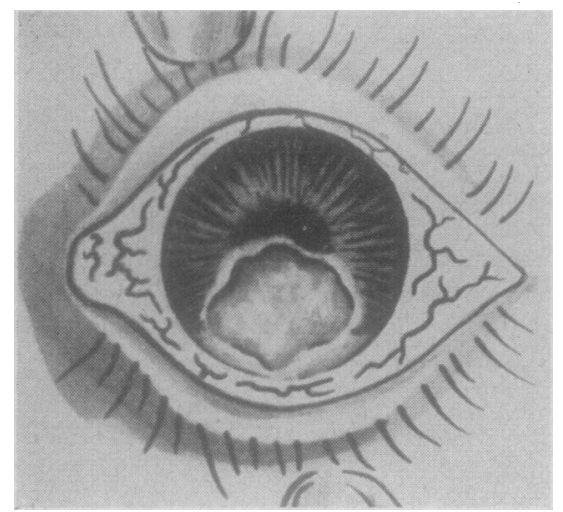

FIG. $4(a)$.-Case 5, left eye, showing ulcer before hooding (Oct. 1947).

well in six days after the usual post-operative treatment.

The patient did not report for opening of the hood until April 26, 1948, see Fig. $4(b)$. After an uneventful operation strong irritation set in which was controlled in eight days by local treatment and the administration of heteroprotein.

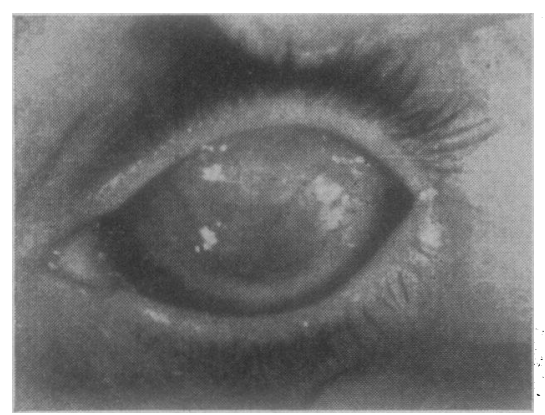

FIG. $4(b)$.-Case 5, left eye, 7 months after hooding, before removal of the hood (April 1948).

Diagnosis: ulcus serpens corneae cum hypopyo o.s.

Bacteriological report: pneumococcus.

The ulcer was painted with 20 per cent. $\mathrm{ZnSO}_{\text {t }}$ once, and besides the usual local treatment the patient was given penicillin drops ( 1 cc. 5,000 units) at intervals of 15 minutes during the day and 30 minutes at night for three days. This treatment was combined with subconjunctival administration of sodium penicillin (10x 30,000 units in 24 hours), further $8 \times 2$ sulphonamide tablets daily and once $0.1 \mathrm{cc}$. typhus vaccine intravenously. ('Temperature $103.8^{\circ} \mathrm{F}$.) Despite this energetic treatment the ulcer continued to grow slowly but steadily, see Fig. $4(a)$. As conservative treatment had no success, a total hooding was performed, which healed

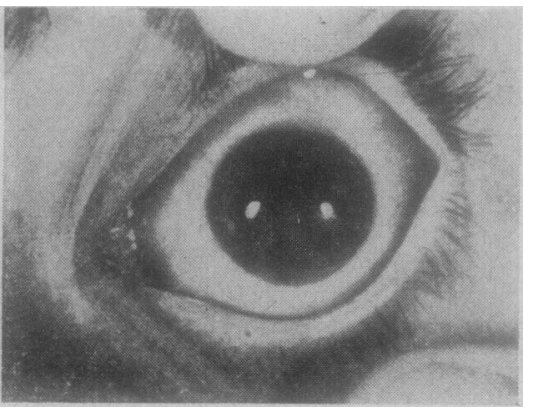

FIG. 4 (c).-Case 5, left eye after removal of hood, cornea entirely healed. Fine, clearly defined scar in place of the ulcer.

V.A. right eye $5 / 5$; left eye hand movements. 
His present condition is V.A. right eye $5 / 5$; left eye $5 / 15$, uncorrectable, see Fig. $4(c)$.

Case 6.-B. F., a peasant aged 82 , was admitted to hospital with a diagnosis of ulcus serpens cornteae cum hypopyo o.d. on July 30,1947. He said that his right eye had been injured by, the thorn of an acacia tree five days previously. The doctor who had treated him had sent him to hospital as his condition deteriorated. There was a typical, not only superficial, but deep serpiginous ulcer with a hypopyon of $2-3 \mathrm{~mm}$.

V.A. right eye, hand movements; left eye $5 / 8$.

Bacteriological report: pneumococcus.

We began by trying penicillin treatment. The patient was given sodium penicillin drops at intervals of 15 minutes in the day and 30 minutes at night (1 cc. 5,000 units). Simultaneously he received $10 \times 30,000$ units penicillin subconjunctivally within 24 hours. But the ulcer continued to grow. On August 2 a total hooding was performed. The next day the eye was slightly still irritated. The patient was given 200,000 units sodium penicillin and one injection of heteroprotein intramuscularly within 24 hours. (Temperature $102 \cdot 2^{\circ} \mathrm{F}$.) After this treatment, complete healing occurred in six days.

The patient returned in July, 1948, for removal of the hood. After an uneventful operation he left hospital five days later.

He returned in three months for an optical iridectomy, and after this had been successfully performed in the nasal direction the V.A. right eye 5/15; left eye $5 / 8$.

Case 7.- N. J., a woman aged 64, was admitted to hospital on June 4, 1948. She said that ten days previously her eye had been injured by the branch of a shrub. She had not seen a doctor.

Diagnosis: Ulcus serpens corneae cum hypopyo et dacryocystitis chr.l.s.

Bacteriological report: pneumococcus.

There was an extremely large ulcer with a small deccemetocele in the centre and a small hypopyon. V.A. right eye $5 / 5$; left eye, perception of light. The uicer was immediately hooded. On the following day the eye was perfectly quiet, so that besides the usual local treatment only typhus vaccine was given intravenously once (temperature $102 \cdot 2^{\circ} \mathrm{F}$.) in order to promote healing. The patient left hospital seven days later.

She returned to have the hood removed on October 27, 1948, the whole cornea being covered by the flap. There was no complisations after the removal of the hood and she left hospital eight days later, completely cured. At present only fine, diffuse scars are visible on the cornea. V.A. right eye $5 / 5$; left eye $5 / 50$, uncorrectable.

Case 8.- E. J., a man aged 28, a carpenter, applied for admission on August 15, 1948. His left eye had been painful for ten days and he had been treated by a doctor. In the centre of his left cornea there was a deep serpiginous ulcer surrounded by a large halo. The ulcer perforated while being examined. The lacrimal sacs were normal.

Diagnosis: ulcus serpens perforans corneae cum hypopyo o.s.

Bacteriological report: pneumococcus.

V.A. right eye 5/5; left eye, perception of light.

The ulcer was immediately hooded. There was an uneventful healing within six days.

Removal of the hood was performed three months later. After the operation considerable irritation set in, which subsided, however, after the usual treatment in ten days. Control June 17, 1949. The centre of the cornea shows a thick leucoma, while the marginal parts are quite clear. In Autumn a keratoplasty which seems very promising in this case will be performed.

Case 9.-Sz. J., a woman aged 56, attended hospital on July 12, 1948 . She said that three days previously a cow had hit her left eye with its tail. On the 
following day her eye began to hurt and she went to see a doctor, who sent her to hospital.

Diagnosis: ulcus serpens corneae cum hypopyo o.s. The lacrimal sacs were normal.

Bacteriological report: pneumococcus.

V.A. right eye $5 / 5$; left eye, only hand movements.

Hooding was carried out immediately. The next day the eye was slightly irritated still, so $10 \times 20,000$ units sodium penicillin were given intramuscularly in 24 hours. The eye healed in ten days.

Four months later the patient came to have the hood removed. The eye was quiet and showed a translucent flap, which entirely covered the cornea. The patient left hospital seven days later. Control on March 10, 1949. V.A. right eye $5 / 5$; left eye $2 / 50$, uncorrectable. We advised optical iridectomy.

Case 10.-K. J., a woman aged 75 , was admitted to hospital on September 1 , 1948. She had already been treated as an out-patient for a refractory ulcer on the temporal side of the left cornea, which had healed after conservative treatment, forming a medium thick scar. About a month later the patient reported again, saying that her eye had been painful for the last three days.

Diagnosis: ulcus serpens corneae cum hypopyo o.s.

Bacteriological report: pneumococcus. The lacrimal sacs were normal.

A total hooding was performed immediately. After the operation strong irritation set in. $10 \times 20,000$ units penicillin were given intramuscularly in 24 hours, as well as heteroprotein every second day. The irritation subsided very slowly. On the 5 th day the flap began to slip upwards, but it stopped at about $2 \mathrm{~mm}$. from the lower margin of the cornea. The patient left hospital after a stay of two weeks.

She returned for removal of the hood on January 30, 1949. After an uneventful operation and the usual post-operative treatment she left hospital eight days later. Control on June 25, 1949, V.A. right eye 5/6; left eye, hand movements (Cataracta totalis).

Case 11.-N. J., a peasant aged 74, admitted to hospital on September 14, 1948. Diagnosis: ulcus serpens corneae cum hypopyo et dacryocystitis chr.l.d. Xerophthalmos 1.s.

The patient stated that the left side of his face had been wounded by a shot in the first world war. Since then his left eye had been blind. His right eye

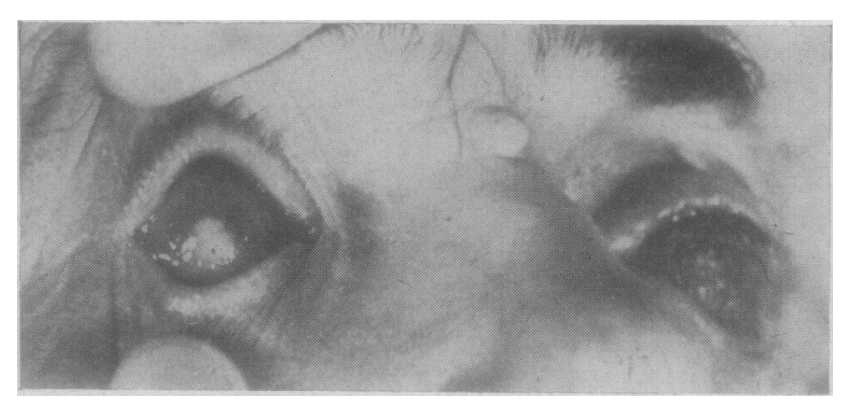

FIG. $5(a)$-Case 11, severe serpiginous ulcer in right eye, xerophthalmos in left eye.

had been injured three days previously by a splinter of wood. He had not consulted a doctor. For the last 24 hours his right eye had been blind, too. (Fig. $5(a)$.) 


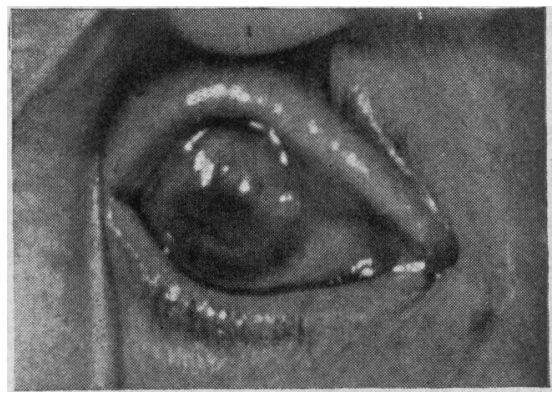

FIG. $5(b)$.-Case 11 , right eye, 3 months after hooding, before removal of the hood.

Bacteriological report: pneumococcus.

V.A. right eye, perception of light; left eye, no perception of light.

Total hooding was performed at once and the diseased lacrimal sacs removed. On the following day the eye was perfectly quiet and it healed in twelve days of local treatment.

The patient came on December 12 , 1948 , to have the hood removed. His cornea was entirely covered by a pale and translucent conjunctiva. (Fig. 5 (b).) After removal of the hood and the usual local treatment the patient was healed in seven days. Control June 3, 1949. The cornea showed a dense scar the size of a pin head, surrounded by fine diffuse cicatrization. (Fig. 5 (c).) V.A. right eye 5/25, uncorrectable; left eye, no perception of light.

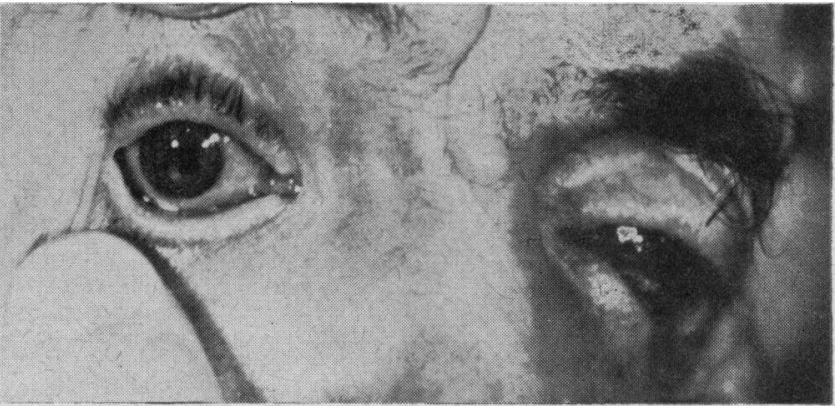

Fig. 5 (c).-Case 11, right eye, showing cornea healed, after removal of hood.

\section{Discussion}

We can only publish cases treated since the summer of 1945 , as the material collected before then was destroyed during the war. We had to make drawings of the first serpiginous ulcers treated with total hooding as we were unable to procure a camera before the spring of 1948. Most of the cases were first treated conservatively, and only when this was of no avail did we resort to total hooding. In a few severe cases, however, hooding had to be performed immediately, so as not to lose a minute in saving the cornea from destruction.

Penicillin.-It is only since 1947 that we have been able to use penicillin. First we administered it intramuscularly without any result whatever; later we instilled drops of a solution of 5,000 units to $1 \mathrm{cc}$. into the conjunctival 'sac at intervals of 15 minutes during the day and 30 minutes at night. With incipient serpiginous 
ulcers this method yielded good results. Of course we tried to increase this good effect by adding dionin and heteroprotein. But as in grave cases this method was not successful either, we tried subconjunctival administration, injecting $10 \times 20,000$ to 30,000 units of penicillin dissolved in 1 cc. 0.9 per cent. sodium solution (that is 200,000 to 300,000 units) daily. But as these in jections were very painful, the solution being hypertonic, we added $0.4 \mathrm{cc}$. 4 per cent. novocaine solution which contained $0.00004 \mathrm{gr}$. adrenalin in $1 \mathrm{cc}$. After the subconjunctival injections of penicillin, the patients always complained of severe pains as soon as the effect of novocaine had ceased, owing to the irritation of the tissues caused by the hypertonic solution. The bulbar conjunctiva became more swollen, hyperaemic, and friable. More unpleasant than all this, however, was the fact that no result was obtained.

In the course of our examinations we soon discovered that with severe serpiginous ulcers penicillin given subconjunctivally was not only of no avail, but also impaired the chances of total hooding on account of the changes in the conjunctiva mentioned above. Grignolo and Bruna (1947) who have made a special study of penicillin treatment of serpiginous ulcers have also found that while it was efficacious in mild cases, it had no effect in medium severe and severe cases, by whatever route it was given. Recently Sorsby and Lngar (1948) have given rabbits $1,000,000$ units crystalline penicillin sub-conjunctivally in 48 hours. In further experiments one injection of 500,000 units was given with satisfactory results. In a few cases of serpiginous ulcers they in jected 200,000 to 500,000 units sub-conjunctivally into human eyes and their results were distinctly promising. It is certain that some cases of incipient or medium severe serpiginous ulcer are responsive to large amounts of penicillin administered subconjunctivally. But the examinations of Grignolo and Bruna as well as our own proved that in the majority of severe cases penicillin was of no avail however it was administered.

We can assume that the reasons for this failure were these. A certain quantity of penicillin which is to be considered as crystaloid can reach the blood stream in the sense of Donnan's equilibrium by the arterial part of the capillaries of the marginal network, through the endothel walls of the arteries. The penicillin which has thus penetrated into the capillary system prolongs the eliminating circumstances of the capillary loops by changing the colloid-osmotic pressure. Owing to the altered osmotic pressure a great part of the penicillin is further eliminated in the lower parts of the capillaries and reaches the cornea with the lymph. It may be assumed that penicillin given subconjunctivally acts as a hypertonic solution and increases the level of penicillin in the 
cornea by changing the osmotic pressure in the conjunctival tissues. The circulation of lymph in the cornea being strongly hindered when large ulcers are present, the quantity of penicillin is necessarily reduced. This probably explains the fact that we were not successful when we treated severe serpiginous ulcers with subconjunctival injections of penicillin. The greater part of penicillin given subconjunctivally reaches the blood stream through the venous resorbing part of the capillary system, and leaves the conjunctiva in a centripetal direction and highly diluted. The lymph in the tissues also carry away the penicillin from the conjunctiva.

As regards the effect of penicillin administered retrobulbarly (500,000 units), it can only be explained by its being resorbed by the veins and the lymphatic system, thus being transferred to the blood stream and into the cornea. This also happens with penicillin given intramuscularly, which does not yield satisfactory results in cases of serpiginous ulcers. Since in severe cases of serpiginous ulcers every minute counts because of their rapid growth, we believe it is useless to resort to a method which is in contradiction to the present anatomical and physiological views.

When the eye became irritated after total hooding we gave penicillin intramuscularly because the conjunctival flap is enlarged and new, and it seems possible to transfer penicillin in adequate concentration to the ulcer through the veins growing into it, and so to promote the healing effect of the hood. It is certain that in some cases irritation was controlled by this treatment and that healing proceeded without complications. (It is true, however, that before the discovery of penicillin, post-operative irritation was sometimes responsive to heteroprotein and local treatment.) We are studying this question which seems theoretically plausible, and if it be possible to transfer adequate quantities of penicillin into the corneal ulcer, we shall use this therapy regularly after every total conjunctival hooding.

\section{Reasons for the Healing Effect of Total Conjunctival Hooding.}

(1) By " anchoring " the conjunctiva to the sclerotic, which is the punctum saliens of this operation, we give the veins enough time to eliminate the débris of the corneal ulcer, to clear the latter, and to ensure a firm coalescence between flap and ulcer. The drawback of Kuhnt-Brückner's flap is that it retracts too quickly, generally before this coalescence could have taken place. Therefore Meisner (1942) is also incorrect in that he placed the suture above the cornea, where " anchoring ", is impossible; the illustration he published as " total hooding", is just Kuhnt's double flap above the cornea. 
(2) Through the veins of the flap, masses of white blood cells rapidly invade the infected site and so the fight against the pneumococci becomes not only possible, but effective.

(3) The bacteriostatic effect of the cellular fluids emerging from the surface of the wound in the flap also promotes healing.

(4) The temperature in the covered cornea rises. This also has a healing effect due to the accelerated metabolism of the cornea.

(5) Besides increased metabolism, mitosis of the corneal cells is stimulated on the one hand and masses of fibroblasts grow into the ulcer and fill jt out on the other.

(6) By total hooding winking of the eyelids which irritates the diseased cornea is eliminated.

(7) Total hooding prevents a new infection by bacteria from the cornea.

Before total hooding was carried out, healed serpiginous ulcers left thick, large, and sometimes ectatic scars, while after total hooding scars are remarkably fine. Thicker leukomata with a clearly defined margin were only present when the ulcer had undermined the cornea to a high degree. The scars occurring after total hooding can be treated with optical iridectomy or corneal transplantation. In several cases which seemed absolutely hopeless satisfactory visual acuity could later be obtained in this way.

Our results are all the more valuable because in over half our cases successful operations were performed on patients of more than 60 years of age. It is well known that while the prognosis in cases of serpiginous ulcer is fairly good with young people, it is poor in old age.

It is interesting that the lacrimal sac was diseased only in four out of the eleven severe cases we published and that this percentage is to be found in almost all the cases of serpiginous ulcer.

Most cases of serpiginous ulcer occur in summer or in early autumn. I believe we are right in assuming that this is not only because of accidents due to agricultural work (injuries caused by cornstalks, wheat ears, maize leaves, etc.); these are undoubtedly important among the causes of serpiginous ulcers, but we must also bear in mind that the virulence of pneumococci in the conjunctiva is intensified by heat so that this disease is more frequent in warm weather. We believe that for this reason severe cases of serpiginous ulcer are rare in western countries with a cooler climate (e.g., in Switzerland, according to Brückner, 1949). A certain time is necessary for the development of the severe type, which depends on the virulence of the pneumococci and the resistance of the cornea. From the literary data we can conclude that in countries 
with a cooler climate the progression of the disease is less rapid, the pneumococci being less virulent. The degree of civilization in various countries is important too. In countries where the population is enlightened enough to ask for medical advice at once, the disease can be treated by a specialist in the incipient stage, so that neglected cases are very rare.

If a serpiginous ulcer is to be treated successfully it is necessary for the patient to see a specialist as soon a possible. While incipient ulcers heal without complications - restitutio ad integrum-great difficulties arise when ulcers have to be dealt with at a later stage. A strong deterioration of visual acuity is always to be expected because of postoperative corneal scars which permanently impair the patient's working ability. Stein is right in saying that this part of the question can be solved by efficient work on the part of the general practitioner.

Another important factor is general popular enlightenment and-last but not least-social insurance for everybody, so that material considerations can no longer prevent patients from going to hospital in time.

Correct Therapy.-When the ulcer is small, conservative treatment should always be resorted to first; this is, local treatment (painting with 20 per cent. $\mathrm{ZnSO}_{4}$, dionin, instillation of penicillin drops at intervals of 15 to 30 minutes, mydriatics) and typhus vaccine as heteroprotein administered intravenously. If all this does not prevent aggression of the ulcer, or if the ulcer is already extensive (especially when situated in the centre) total hooding should be performed without delay.

\section{Summary}

We consider total conjunctival hooding the most efficacious method for healing serpiginous ulcers. This is proved by more than 150 successful operations, including the cases already published by Kettesy. In the incipient or medium severe stage of the disease the usual conservative treatment ought always to be attempted, and only when this is not successful should hooding be performed. In severe cases, hooding should be carried out immediately so as to prevent further losses. Our experience has shown that with grave ulcers the effect of penicillin is not satisfactory by whatever route it may be administered. It may, however, promote healing when given intramuscularly after total hooding.

To ensure full success of total hooding it is essential to prevent traction of the conjunctival flap, and to " anchor" the latter to the sclerotic in three places $2 \mathrm{~mm}$. below the limbus. 
The hood should only be removed when the eye is absolutely quiet and pale. This depends on the gravity of the ulcer and generally takes 2 to 3 months.

After total hooding the patients need not remain in hospital as long as when they are treated in the conservative way; thus they can return to work after much shorter a time. Visual acuity is much better after total hooding and final invalidity is also considerably reduced.

We have been performing total hooding for more than eight years and only two out of all our cases were lost. Therefore we think that this method should be used frequently, not only in cases of serpiginous ulcers, but in all cases of serious corneal ulcers.

\section{REFERENCES}

BirCh-HiRSChFELd, G. (1920). Z. Augenheilk., 44, 1.

Blaskovics, L. von, and Kreiker, A. (1945). "Eingriffe am Auge", 2nd ed., p. 258. Enke, Stuttgart.

BR ̈̈CKNER, A. (1949). Comment on Stein's lecture, Ophthalmologica, Basel, 117, 236.

B̈̈rk I, E. (1948). In "Lehrbuch der Augenheilkunde", ed. M. Amsler and others, p. 480-483. Karger, Basel.

Clausen, W. (1931). Klin. Mbl. Augenheilk., 87, 832.

Clerici, A. (1934). Rass. ital. Ottalm., 3, 683.

ERGGELET, H. (1931). Klin. Mbl. Angenheilk., 87, 831.

Grignolo, A., and BrunA, F. (1947). Boll. Oculist, 26, 630.

Kettesy, A. (1948). British Journal of Ophthalmology, 32, 36.

Kreiker, A. (1933). Klin. Mbl. Augenheilk., 90, 373.

LAWAET $Z$, B. (1943). Zbl. Ophthal., 49, 55.

Löhlein, W. (1931). Klin. Mbl. Augenheilk., 87, 832.

Meisner, W. (1942). In "Ophthalmologische Operationslehre", ed. R. Thiel, 1, 242. Thieme, Leipzig.

Miklós (1941). Klin. Mbl. Augenheilk., 107, 138.

RubBrecht, R. (1931). Bull. Soc. franc. Ophtal., 44, 331.

SCHIECK, F., and BR̈̈́CKNer, A. (1931). "Kurzes Handbuch der Ophthalmologie", 4, 454. Springer, Berlin.

Sondermann, R. (1922). Klin. Mbl. Augenheilk., 69, 759.

SORSBY, A., and REED, H. (1947). British Journal of Ophthalmology, 31, 528.

and UNGAR, J. (1948). Ibid., 32, 857, 864, 873, 878.

Stein, A. (1949). Ophthalmologica, Basel, 117, 237.

Wessely, K. (1926). Dtsch. med. Wschr., 52, 17. 